\title{
Immersive and cultural transformation of the system of additional education as a tool for the development of environmental and social responsibility of the society
}

\author{
Roman Oparin ${ }^{1,2,}$, Elena Arbuzova ${ }^{3,4,5}$, and Sergey Nazarov ${ }^{6}$ \\ ${ }^{1}$ Moscow State Regional University, Russia \\ ${ }^{2}$ Novosibirsk State Pedagogical University, Russia \\ ${ }^{3}$ Omsk Academy of Humanities, Russia \\ ${ }^{4}$ Omsk State University named after F.M. Dostoevsky, Russia \\ ${ }^{5}$ Moscow State Regional University, Russia \\ ${ }^{6}$ Omsk State Pedagogical University, Russia
}

\begin{abstract}
The article scientifically substantiates the cultural and creative concept of additional environmental education, as a methodological basis for the formation and development of environmental and social responsibility, which involves the development of four levels of value orientations of students: reproductive, heuristic, creative. The concept is aimed at the formation of the individual activity of students in solving environmental problems on the basis of social, scientific and aesthetic axiological systems that determine the content of ecological-biotechnical, ecological-research, ecological-aesthetic activities. The main result of the implementation of this concept is the ability of students to plan their activities for the study, preservation and creative transformation of the environment independently, using traditional and immersive technologies. Scientists have designed a cultural and creative system of additional environmental education for students using immersive learning technologies, which is considered as a tool for the development of environmental and social responsibility of society. The article presents the results of an experimental test of the effectiveness of the cultural and creative system of additional environmental education using traditional and immersive learning technologies, which has shown the high effectiveness of the influence of innovative forms, means and methods of additional environmental education in the formation of environmental value orientations of students.
\end{abstract}

\section{Introduction}

In the context of global environmental problems and the inevitably impending environmental crisis on the planet, to ensure the survival of mankind, both cardinal political, technological, science-intensive solutions and innovative changes in the field of socio-economic and

\footnotetext{
*Corresponding author: 89236613134@inbox.ru
} 
cultural policy, especially in the field of education, are required. In this context, the determining factor is the rethinking of the traditional value and worldview attitudes that determine the attitude to nature, the degree of its transformation, the formation of a balanced lifestyle of a person, his ecologically balanced needs. According to the Concept and Goals of Sustainable Development adopted by the world community, by 2030 the priority areas of education are the formation of a new world outlook, lifestyle, culture of sustainable development, based on the modern scientific picture of the world, the values of environmentally sustainable development, the ability to identify in the surrounding world interconnections of natural, economic and social processes, global, local and personal, past, present and future; as well as experience of practical actions in the interests of sustainable development of the local community.

Continuous environmental education acts as a platform for the implementation of education for sustainable development in many countries of the world, as in our country. In fact, this is a new social order for the environmental education system at all its levels, including in the system of additional education. The field of additional education carries a huge potential for the formation of environmental and social responsibility, since it provides students with an independent choice of an educational trajectory, integrating humanitarian, natural science and practice-oriented approaches to environmental education. This approach to additional environmental education does not "cancel", but complements classical education in the field of bio ecology and geo ecology, significantly changing the ideas about the goals and methods of ecologization of the educational process, the content of the environmental competence of teachers, the role of general education in its formation.

An important direction in the development of additional environmental education is its information and digital orientation. A new generation of students (generation Z, children of the 2000s [1]) lives in a digital environment, which is formed by immersive technologies, including such educationally significant ones as immersive technologies [2]: $3 \mathrm{D}$ visualization technologies, virtual, augmented, mixed reality, $360^{\circ}$ video, virtual laboratories, cryolized hypertexts, etc. The relevance and significance of the use of immersive technologies in all areas of education is reflected in the new UNESCO recommendations ("UNESCO ICT Competency Framework for Teachers. VERSION 3", 2018) [3], corresponding to "The 2030 Agenda for Sustainable Development" adopted by the UN General Assembly [4].

Summarizing the above approaches to the study of the problem of environmental education, it should be noted that there have been no special studies devoted to the design of an innovative system of additional environmental education as an integrating factor of the general education system in terms of the formation of environmental and social responsibility of society. This urgent problem, in our opinion, requires further research, especially in terms of conceptualization and development of methodological and technological aspects. Without solving this problem, the continuity of the formation of an ecological culture of general additional, university and postgraduate education is violated. The educational process takes place without a sufficiently complete and deep substantiation of the methodological, theoretical and technological foundations of environmental education.

The relevance of the research topic determined the scientific problem of the research, which is the search for an answer to the question: "What should the system of additional environmental education be, which would effectively form the environmental and social responsibility of society?"

The basic idea of the research is to form students' environmental and social responsibility in the system of additional environmental education based on the cultural concept with the use of immersive technologies.

The purpose of the study is to increase the level of environmental and social responsibility of students through the use of a cultural-creative system of additional environmental education in the educational process with the use of immersive learning technologies. 


\section{Materials and Methods}

The main idea of the Cultural concept, analyzed in the context of our article, is the cultural and cultural edifying role of the student's personality. Environmental education within the framework of this concept is understood not only as a reproducing activity, ensuring the maintenance of the achieved level in social and ecological development, but also as the creativity of the student's personality, aimed not only at the assignment (de-objectification) of cultural values (at the level of environmental value orientations), their preservation (maintenance and restoration of natural and cultural heritage), but also the creation of something new in culture (artistic and creative transformation of the environment).

The main theoretical positions, on which the cultural concept is built, include four main components.

1. The activity of the object of pedagogical influence, aimed at the study, preservation and artistic and creative transformation of the surrounding socio-natural environment. An important guideline for such activities is the system of environmental value orientations, acquired in the procedures of empathy, active involvement, personal participation in solving environmental problems, on the scale of their region - in particular, and our planet - as a whole.

2. The activity of the subject of pedagogical influence sets the algorithms for an ecological-upbringing dialogue with an object in the process of mastering ecological value orientations and diagnosing the quality of this mastery. The activity of the subject allows the progressive development of environmental and social responsibility to be deployed in the spatial vector of environmental education.

3. Environmental and social responsibility and environmental value orientations as an indicator of their formation are the main, system-forming component of the spiritual and material space of the concept.

4. Diagnostics at each age stage of environmental education has a common vector of consistent correction of the development of environmental value orientations of the individual, building in the mind of the pupil a holistic picture of nature and man in it. At each level of diagnostics, its own intermediate goals, problem-content and psychologicalpedagogical determinants are distinguished, which makes it possible to build horizontal interdisciplinary connections, to model in the interaction of forms and means of cultural activity the axiological space to be mastered.

- The interaction of the activities of a teacher, student and diagnostic tools in the field of formation and development of environmental value orientations is carried out in the axiological space of the concept. The axiological space includes a system of ecological value orientations, which we differentiate into eight groups: vital and biological; ecological and social; ecological-patriotic; ecological and ethical; ecological and aesthetic; environmental research; ethno-ecological and pedagogical.

- The implementation of the cultural and creative concept of environmental education in the vector of the formation of environmental value orientations presupposes an awareness of the multilevel nature of cultural and educational activities. Taking into account the stages of the formation of environmental and social responsibility (ID Zverev [5], IT Suravegina [6]) as well as the psychological and physiological characteristics of this group (IV Shapovalenko [7], VA Yasvin [ 8]) we have identified four levels of development of ecological value orientations, each of which determines the content of forms and means of ecological education.

- The adaptive level is the starting one and is characterized by an unstable attitude of students to the development of value orientations that are within the vital biological axiological group. The system of ecological value orientations, for the most part, is absent. 
- The reproductive level is manifested in the motivation to assimilate the spiritual ecological values of one's ethnic group and the ways of their interpretation, based on the algorithmic model proposed by the teacher. Students maintain constant contact with the teacher and have self-control over their activities and their effectiveness. At the same time, the degree of independence of students is rather low.

- The heuristic level is characterized by greater purposefulness, stability, awareness of the development of environmental moral and patriotic values. Guided by them, the student continues to seek and discover new ways of environmentally sound solutions. It increases the independence and the creative activity of the students, their ability to plan individual operations when solving environmental problems at the local level.

- The creative level is characterized by a high degree of effectiveness of the individual activities of students in solving environmental problems on the basis of social, scientific and aesthetic axiological systems that determine the content of ecological-biotechnical (environmental), ecological-research (scientific), ecological-aesthetic (associated with the creative transformation of the environment ) activities. The structure of the student's personality harmoniously combines scientific and practical interests in the field of ecology, a high level of reflection and creative independence. The main characteristic of achieving this level of development of value orientations is the ability to independently plan their activities for the study, preservation and creative transformation of the environment.

Thus, we consider the cultural-creative concept as a system of ideas, views, attitudes, which should serve as a starting theoretical base, a strategic guideline for a specific search for the necessary model of modern environmental education in the context of the development of environmental and social responsibility of society.

\section{Results and Discussion}

The main task of the first series of experiments was to prove that the system of additional environmental education developed on the basis of the formulated conceptual provisions creates conditions for the holistic and effective formation of environmental value orientations of students.

The first series of experiments showed a fairly high efficiency of the influence of innovative forms of cultural and educational activities (environmental and cultural training, environmental movements, interactive games; environmental and cultural excursions, ethnoenvironmental expositions, environmental and cultural clubs) on the formation of environmental value orientations. So, in the experimental groups of students at the reproductive, heuristic and creative stages of the development of ecological value orientations, the curves of the levels of formation of their main determinants are, on average, $14-25 \%$ higher than in the control groups.

The second series of experiments showed a fairly high efficiency of the means of organizational and methodological support (on the example of the special course "Altai Zapovedny") in the formation of ecological value orientations of schoolchildren in the context of national and cultural values. The high and above average levels of development of ecological value orientations, taking into account the regional aspect, in the experimental group are from 39.3 to $41.2 \%$, while in the control group the similar levels are from 34.5 to $35.6 \%$.

The third series of experiments showed that the most effective forms and methods for the development of ecological value orientations of schoolchildren are practical cultural and educational activities of an ecological orientation (cultural and creative practices that are revealed through the ecological-local history, ecological-biotechnical and ecologicalaesthetic directions). Thus, the level of formation of the cultural and creative determinant of the ecological value orientations of "eco-researchers" is on average $21.2 \%$ - than that of 
senior pupils and students of the control group. The level of formation of the cultural determinant of the ecological value orientations of "eco-designers" is, on average, $25.9 \%$ higher than in the control.

The reliability of the experimental results was determined on the basis of the $\mathrm{X}^{2}$ (chisquare) goodness-of-fit criterion at a significance level of 0.05 . On the basis of this criterion, the hypotheses put forward about the statistical significance of the observed differences in the control and experimental groups at the initial and final stages of training are tested. The calculation results show that Tnabl $\geq$ Tkrit, which confirms the reliability of the results of our research.
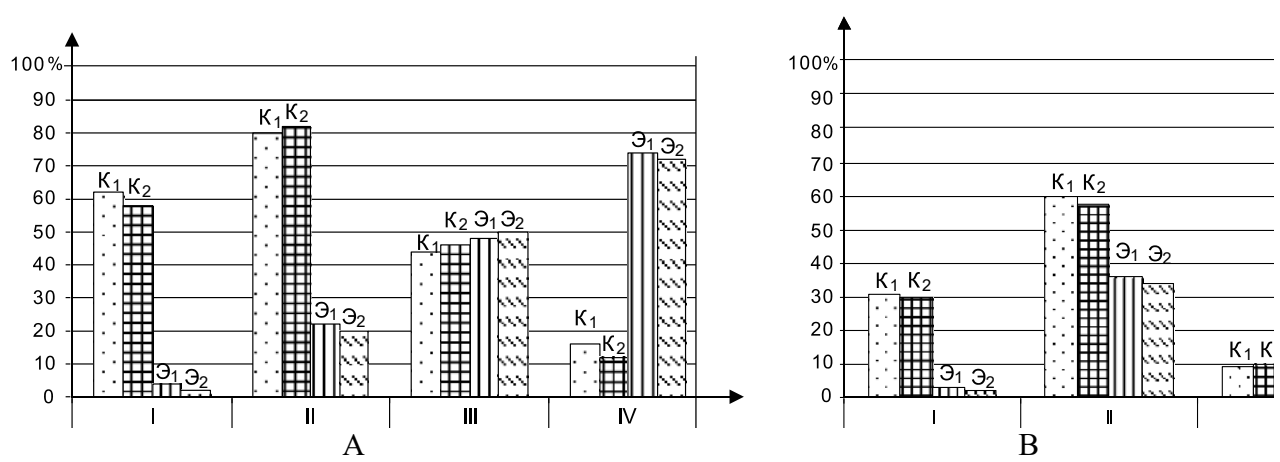

Fig. 1. Formation of environmental and social responsibility of students of the first (A) and second (B) series of experiments. C1 - control group No. 1; C2 - control group No. 2; E1 - experimental. group No. 1; E2 - experimental group No. 2.

\section{Conclusion}

In the course of the study, the following results, reflecting its novelty, theoretical and practical significance were obtained.

1. The cultural and creative concept of additional environmental education has been scientifically substantiated as a methodological basis for the formation and development of environmental and social responsibility using a complex of immersive technologies. The main result of the implementation of this concept is the ability to plan their activities for the study, preservation and creative transformation of the environment independently, using traditional and immersive technologies.

2. A cultural-creative system of additional environmental education for students has been designed using immersive learning technologies, the conditions for the effective functioning of which are: cultural-creative orientation (providing for the ordering of levels and types of additional environmental education due to the idea of environmental cultural creativity), dynamism (ensuring the formation and development of environmental value orientations through a set of innovative forms and means of interaction between a teacher and a student in a natural and immersive environment), predictiveness (determining the possibility of assessing indicators of the formation of environmental value orientations using the technology of axiological diagnostics of the results of environmental education using immersive technologies).

3. A regionally-oriented software and methodological complex has been created, including a package of software and normative documentation, a set of management tools for the implementation of environmental education, scientific and methodological recommendations for its organization, a set of methods regulating the current and final diagnostics. The effectiveness of the relationship of forms, means and methods within the 
framework of the implementation of the regional program and methodological complex was monitored in all the listed structures using a system of competence trainings, the results of which were used as the basis for the experimental part of the work [9].

4. Experimental and experimental testing of the effectiveness of the cultural and creative system of additional environmental education using traditional and immersive learning technologies was carried out, which showed the high efficiency of the influence of innovative forms, means and methods of additional environmental education in the formation of environmental value orientations of students. The most effective forms and methods are the inclusion of students in practical cultural and educational activities of environmental orientation (interactive exhibitions, virtual polygons, interactive games and AR-quests) [10].

So, in the course of the study, it was confirmed that the cultural concept and the system of organizational and methodological support create favorable conditions for the implementation of additional environmental education for students. Experimental testing of its effectiveness has confirmed the advisability of choosing the forms and means of environmental education, showing a high level of development by students of environmental value orientations, a wide range of use of skills in the field of ecology and nature protection.

The authors do not consider this study to be exhaustive; research prospects can be associated with the further development of immersive technologies in the theory and practice of environmental education.

\section{References}

1. V.I. Blinov, Draft didactic concept for digital vocational education and training, 72 (2019)

2. I.V. Robert, Pedagogical informatics, 3, 141 (2020)

3. UNESCO ICT Competency Framework for Teachers. VERSION 3, (2018), gcedclearinghouse.org

4. The 2030 Agenda for Sustainable Development. Official site of UNESCO (Russian version), https://www.un.org

5. I.D. Zverev, Formation of ecological education in Primorsk Territory. Those trends and perspectives. Materials for the conference, 16 (1998)

6. I.T. Suravegina, Theory and practice of the formation of a responsible attitude of students to nature in the process of teaching biology: avtoef. dis., 215 (1996)

7. I.V. Shapovalenko, Developmental psychology and developmental psychology, 349 (2014)

8. S.D. Deryabo, Methods of diagnostics and correction of attitude to nature, 147 (1995)

9. R. Oparin, E3S Web of Conferences 210, 22033, Annual scientific conference "Innovative technologies in science and education" (2020), https://itno.donstu.ru/

10. R. Oparin, SAHD 2021 - 5th International Scientific and Practical Conference 2021 "Modern Science: Problems and Development Prospects" (Social and Humanitarian Directions), 101 (03018) (2021) 